\title{
MORTALIDADE NÃO-PREDATÓRIA DE MICROCRUSTÁCEOS PLANCTÔNICOS EM UM RESERVATÓRIO DO NORDESTE DO BRASIL
}

\author{
Neves, F.G.R.C. ${ }^{1,}{ }^{*}$; Severiano, J.S. ${ }^{\text {; }}$ Morais Junior, C.S. ${ }^{\text {; }}$ Santos, D.S. ${ }^{1}$; Silva, A.J. ${ }^{1}$, \\ Santos, F.A. ${ }^{1}$ \& Melo Júnior, M. ${ }^{1}$ \\ ${ }^{1}$ Universidade Federal Rural de Pernambuco (UFRPE), Campus Recife, Laboratório de Ecologia do Plâncton. \\ *Autor correspondente: filipegneves@hotmail.com
}

Os microcrustáceos são importantes grupos do zooplâncton de reservatórios e respondem às condições ambientais de diversas formas, incluindo a mortalidade não-predatória. Este estudo teve como objetivo caracterizar a mortalidade da comunidade de microcrustáceos planctônicos em diferentes condições ambientais em um reservatório do Nordeste do Brasil. As amostras de zooplâncton foram obtidas através da filtragem de 100L de água, em rede de plâncton $(45 \mu \mathrm{m})$, e fixadas em formol neutro (4\%). Os percentuais de mortalidade foram obtidos a partir da técnica do azul de anilina, que permite diferenciar indivíduos mortos (corados) dos vivos (não corados). A comunidade foi avaliada quanto à densidade (ind. $\mathrm{m}^{-3}$ ), abundância relativa, diversidade $\left(H^{\prime}\right)$ e proporção de mortos. Foram aplicados (i) correlação de Pearson, para verificar possíveis relações entre a comunidade e os parâmetros ambientais, (ii) teste $t$, para avaliar a mortalidade quanto às estações (seca e chuvosa), fotoperíodo (diurno e noturno), região (limnética e litorânea), (iii) ANOVA, para as zonas (lêntica, transição e lótica), e (iv) IndVal para analisar potenciais espécies indicadoras. A comunidade de microcrustáceos foi composta por copépodos e cladóceros, sendo os primeiros representados principalmente por náuplios de Cyclopoida (50\%) e Notodiaptomus cearensis (21\%), enquanto que para os cladóceros, as espécies mais representativas foram Diaphanosoma spinulosum (35\%) e Ceriodaphnia cornuta (22\%). A maior diversidade foi observada no período seco $\left(H^{\prime}=0,99 \pm 0,36\right.$ bits. ind $\left.{ }^{-1}\right)$. A espécie com maior indicação ambiental foi $C$. cornuta, para estação seca, temperatura $>26,4^{\circ} \mathrm{C}$, turbidez $>12,5$ e oxigênio superior a 3,8. A mortalidade dos microcrustáceos variou de 16 a 97\%, não havendo correlação com nenhum parâmetro ambiental nem diferenças considerando as regiões e zonas do reservatório e o fotoperíodo. Por outro lado, foram registrados maiores percentuais de mortos na estação chuvosa (teste $t, \mathrm{p}=0.0003$ ). Baseada em método tradicional, a densidade média de microcrustáceos foi de 110.104 ind. $\mathrm{m}^{-3}$. Entretanto, ao considerar o percentual de mortalidade média obtida $(65,1 \%)$, esse valor diminui consideravelmente (64.520 ind. $\left.\mathrm{m}^{-3}\right)$. Este estudo demonstra que a concentração de carcaças pode influenciar a estimativa da densidade de microcrustáceos disponíveis em reservatórios, ao considerar a parcela de mortos.

Palavras-chave: ambiente aquático, Crustacea, zooplâncton, carcaças, azul de anilina. 